\title{
Linguistic and Cognitive Characteristics of the Composition of the Text of J.K. Rowling's English Tales
}

\author{
Elena Solodova \\ Sevastopol State University, Ukraine \\ E-mail: lencha_igor@rambler.ru
}

Doi:10.7575/aiac.alls.v.6n.5p.151

Received: 17/05/2015

URL: http://dx.doi.org/10.7575/aiac.alls.v.6n.5p.151

Accepted: 29/07/2015

\begin{abstract}
This article focuses on linguistic and cognitive characteristics inherent in the composition of the English postmodern tales written by J.K. Rowling. The composition of the text is viewed as linguistic and cognitive construal that integrates compositional plot structure, compositional meaning structure, linguistic and stylistic means of their actualization in the text. The content of the text is organized as a specific configuration of compositional plot blocks reflecting similar topics of textual situations. The coherence and cohesion of compositional plot blocks are provided by the compositional devices which perform text building and text forming functions. Compositional meaning structure is revealed via reconstruction of the conceptual metaphoric and metonymic schemas embodied in compositional plot blocks. The key meaning is represented by the megametaphor LIFE IS THE CHOICE OF A PATH, which in the text unfolds into a number of conceptual metaphors and metonymies. The peculiarities of representation of compositional plot structure and compositional meaning structure are explained through the analysis of corresponding linguistic and stylistic means and types of narration.
\end{abstract}

Keywords: Composition, Linguo-cognitive construal, Compositional plot structure, Compositional meaning structure, Compositional plot blocks, Conceptual megametaphor

\section{Introduction}

In this article linguistic and cognitive peculiarities of composition of the English modern author's tales exemplified in J.K. Rowling's books are analysed. Linguistic and cognitive approach to the present research gives way to elicit the nature of the relations between the content, meaning of the text of the tales and its verbal realization.

Linguistic and cognitive research of the composition of the artistic text originated in the depth of historical, structural and semantic poetics long before the scientific legalization of cognitive linguistics as a paradigm of knowledge. However, the study of composition within the linguistic and cognitive aspect proposes to use not only achievements of the previous scientific paradigm but also the development of a new one, in particular, the division of the composition into outer and inner one.

Within the linguistic and cognitive approach to the study of composition the focus of attention is shifted to the revealing and analysis of the cognitive mechanisms of structuring the knowledge of the world, the impulse for the activation of which is the number of the linguistic forms, conceptualized on the verbal layer of the composition of the text (Rastorgueva, 2005).

Progressive enough for its time the understanding of the composition of the artistic text as the construal of conscience belongs to Propp: "The composition does not really exist so as there are no general notions in the material world: they exist only in the conscience of a man. But it is general notions that help us to perceive the world, reveal its laws and learn to govern them" (Propp, 1969). Compare: "The ground of the compositional plot structure of the text is the mental model since it represents its reference (Tomashevsky, 1959).

The background to the linguistic and cognitive approach to the composition is traced in the works of Lotman, who proposed that between live situations and "lyrical situations" there is a coding system, which explains the way the phenomena of the world of reality are reflected in the construction of the text. One of the main coding system of such kind is the structure of the artistic thinking (Lotman, 1996).

In the researches devoted to the linguistic and cognitive analysis of the texts of the tales there was an attempt to reconstruct the compositional structure of its content. So, for example, in the research of Eremeeva (1997) the compositional structure of the content of the English folk tales is proposed, in which the generalized images of the characters are presented as the subjects of the propositional structures, endued by static (qualitative) and dynamic (functional) attributes. 
Within the cognitive study the productive appeared to be the approach to the study of the text as the space. In the categories of space the text is viewed not only as complex of line arranged signs but also as a complex of senses (Babenko, 2004).

Under the influence of a new paradigm of knowledge, the cognitive linguistics, the presentation of semantic organization of the artistic text has principally changed and enriched. Already from the new positions the division of the semantic space of the text in the categories of content and sense is considered.

The applicability of this article is grounded on the world-wide popularity of J.K. Rowling's tales, the increased interest to the study of postmodern texts in whole and tales in particular, as well as the common tendency to the linguistic phenomenon complex analysis in order to explain its form, content and meaning. This tendency manifests itself in the cognitive poetics - the theory of the text where the problem of language and thought interaction is solved by the interpretation of literary texts via revealing and explanation of creative mechanisms of formation of hidden senses through their conceptual content explication, as well as through extraction of their peculiarities of the compositional organization of literary texts.

To describe the composition of the text of the tales the working hypothesis was formulated according to which the composition of both literary texts and the text of the tales is understood as the way of organizing the text which provides the cohesion of its form, content and meaning. Hence the composition is viewed as linguistic and cognitive construal comprising compositional plot structure (the way to organize content), which depicts the literary handling of the events exposed in the text, as well as compositional meaning structure, which provides the meaning interpretation. The peculiarities of embodiment of both structures, i.e. the way of its formal presentation, are defined by the analysis of corresponding linguistic and stylistic means and compositional speech forms.

Due to the fact that while describing the plot the attention is given to the event and situation of textual fragments of the work (Halizev, 1999; Chernets, 1999) it is reasonable to consider textual situations as key components of the compositional plot structure. The textual situation is understood as fragment of the text, which describes definite events and reveals definite theme. The semantic core of textual situation is considered to be the motive, which is defined as theme dominant of textual situation educed via its informational squeezing and denoted by one or two lexical units called theme words. In textual situation the motive is realized in the key element (word combination or sentence) and semantic correlate. The difference between them is that the key element may possess lexical unit that can be used as possible denomination of the motive, while there is no such lexical unit in semantic correlate. Applying the poetological analysis method of Nikonova (2007) we establish the relation of assimilation and opposition as well as cause-and-effect and metonymic relations.

The repetitiveness of homogeneous textual situations conditioned by the serial character of postmodern tales affords ground to unite them into plot blocks. Each plot block is structured by textual situations, which depict the key events of the tale. In each plot block textual situations are correlated with common theme. Between the motive and plot block we identify both cause-and-effect relations and relation of concretization when the motive defines the content of the whole plot block and compiles its denomination.

In the result of contextual and situational as well as interpretative and textual analyses of textual situations of the tale the following plot blocks were educed: "The residence of the main character in the foster family", "The passage into the fairy world", "The competition", "The secret and its disclosure", "The antagonism of light and dark forces", "The explanation".

The coherence and cohesion of the plot blocks as well as organization of the conceptual space of the tale is provided by the compositional devices. In our research we understand the compositional device as the compositional mean, highlighting the key categories and properties of the text of the tale (literary time and space, intertextuality, literary worlds of the tale) and provides the coherence of its content. The compositional devices perform text building and text forming functions being not only technical device but also compositional meaning one.

In the text of J.K. Rowling's tales we revealed the following compositional devices: literary time and space actualization device, the device of the manipulation of the worlds, intertextuality device, device of the opposition of the real and fairy worlds.

\section{Literary time and space actualization device}

In the tales about Harry Potter the topophones of real and fairy worlds are crossed. If in the folk tale the magic happens either in the frontier territory (porch) or in the fairy topophone (Far Far Away Kingdom), in the analyzed tales the magic takes place in the reality as well. The last one is alien and hostile to the main character:

Harry was used to spiders, because the cupboard under the stairs was full of them, and that was where he slept (Harry Potter and the Philosopher's Stone).

In contrast, the fairy topophone is friendly to the main character:

The castle felt more like home than Privet Drive had ever done (Harry Potter and the Chamber of Secrets).

In J.K. Rowling's tales the leaps in time and space are traced which are realized by using the fairy attributes: Time Tuner - the peculiar time machine, Portkey - the portal which can be any thing or object of the reality providing the 
transition from the real world into the fairy one and back. For instance, the old shoe. The peculiarities of the actualization of the literary time and space appear while using Pensive - the attribute by which the transition from physical into mental space is realized:

He took a great gulp of breath, and plunged his face into surface of Snape's thoughts (Harry Potter and the Order of Phoenix).

One of the compositional key devices in the revealing of the compositional plot structure is the compositional device of the manipulation of the worlds. It is actualized by combination of attributes of real and fairy topophones providing the depiction of modern reality inherent in the text of postmodern epoch. For example, the fairy world of J.K. Rowling's tales has the realia typical for the modern state: the International Warlock Convention of 1289, the Magical Law Enforcement Patrol, Ministry of Magic, wizard's bank Gringotts, wizard's prison Azkaban. In the text of tales some other realia of the modern world of people can be met: the shop of second-hand cloth, advertisements and even the hint at racism. However, unlike the world of people where the colour of skin defines what race a man belongs to and can be the cause of discrimination, in J.K. Rowling's tales the origin of magician performs this function:

"No one asked your opinion, you filthy little Mudblood, he spat” (Harry Potter and the Chamber of Secrets).

The intertextuality device is embodied via the mythological images, the names of the characters and the "speaking" names and fairy attributes. The examples of mythological images are images of the fantastic creatures borrowed from myths of Ancient Greece and The British Isles: dragon, Phoenix, centaurs, unicorn, Basilisk, werewolf, poltergeist, Cornish pixies, Yeti, Bandon Banshee, Red Caps, Grindylow, ghoul, Dobie, boggart, Grim, goblin, dwarf, vela, leprechaun. The examples of fairy attributes are wand, broom, Invisibility Cloak, self-filling plate, mirror of desire, mythological plant Mandrake the mention of which we can find in biblical legends of Mandrake Apple. Moreover, in the texts of J.K. Rowling's tales Order of Merlin is mentioned, the realia, borrowed from medieval Celtic narrative of King Arthur. The names of characters are taken from the different mythological and literary sources: Minerva (Roman mythology), Circea (Greek mythology), Alberic (German and Scandinavian mythology), Padma (Indian mythology), Hermione Granger (William Shakespeare's play “The Winter's Tale”), Fang (allusion to the character of J. London's novel "The White Fang").

The peculiarity of J.K. Rowling's idiostyle is the creation of neologisms that can be referred to the so-called "speaking" names. Lucius Malfoy is the example of such "speaking" name in the inner form of which there is allusion to Lucifer (The Bible). The son of Lucius Malfoy - Drako Malfoy, one of the main character's foes within the fairy school, also possesses the momentous name. Draco translated from the Latin means "dragon" or "snake". Malfoy is derived from the Latin word maleficus, which means "villain" (Fr. mal foy - "the one who can not be relied on"). In the Medieval the witches were called malefica. The antagonist of the tale the dark Lord Voldemort is also endowed with "speaking" name. It can be translated from the Latin as "the one who wants death" (Lat. volo - I want; Lat. mors - death). For the bearers of the Russian culture the name Voldemort is allusion to Voland, the character of M. Bulgakov's novel "The Master and Margarita", personifying the image of Satan.

The opposition of locuses of real and fairy worlds is achieved through the compositional device of opposition of real and fairy worlds. Between the common and fairy spaces there is opposition friend/foe. It is typical that in the common topophone Harry Potter acts as classic fairy protagonist - destitute, persecuted, oppressed adopted son. It concerns the way the main character eats:

Harry washed his hands and bolted down his pitiful supper (Harry Potter and the Chamber of Secrets).

The word image pitiful supper is created by mapping of the attribute of purpose domain SUPPER to source domain THE MAN WHO SUFFERS PITTINESS (looking at the supper). Let's take another example:

Aunt Petunia's hand appeared, pushing a bowl of tinned soup into the room. Harry, whose insides were aching with hunger, jumped off his bed and seized it. The soup was stone cold, but he drank half of it in one gulp (Harry Potter and the Chamber of Secrets).

The quality of soup, served to Harry, is characterized by stone cold epithet. The emphasis on inedibility of cold soup is made by cross mapping of attributes of purpose domain SOUP and source domain STONE.

By means of the compositional device of opposition of real and fairy worlds the author depicts the opposite picture in the family of Ron, Harry Potter's best friend. Here Harry is treated kindly and feasted lavishly:

"'I don't blame you, dear', she assured Harry, tipping eight or nine sausages onto his plate" (Harry Potter and the Chamber of Secrets).

The cohesion of educed plot blocks and extracted compositional devices allows to model the compositional plot structure in the form of the following scheme (fig. 1): 


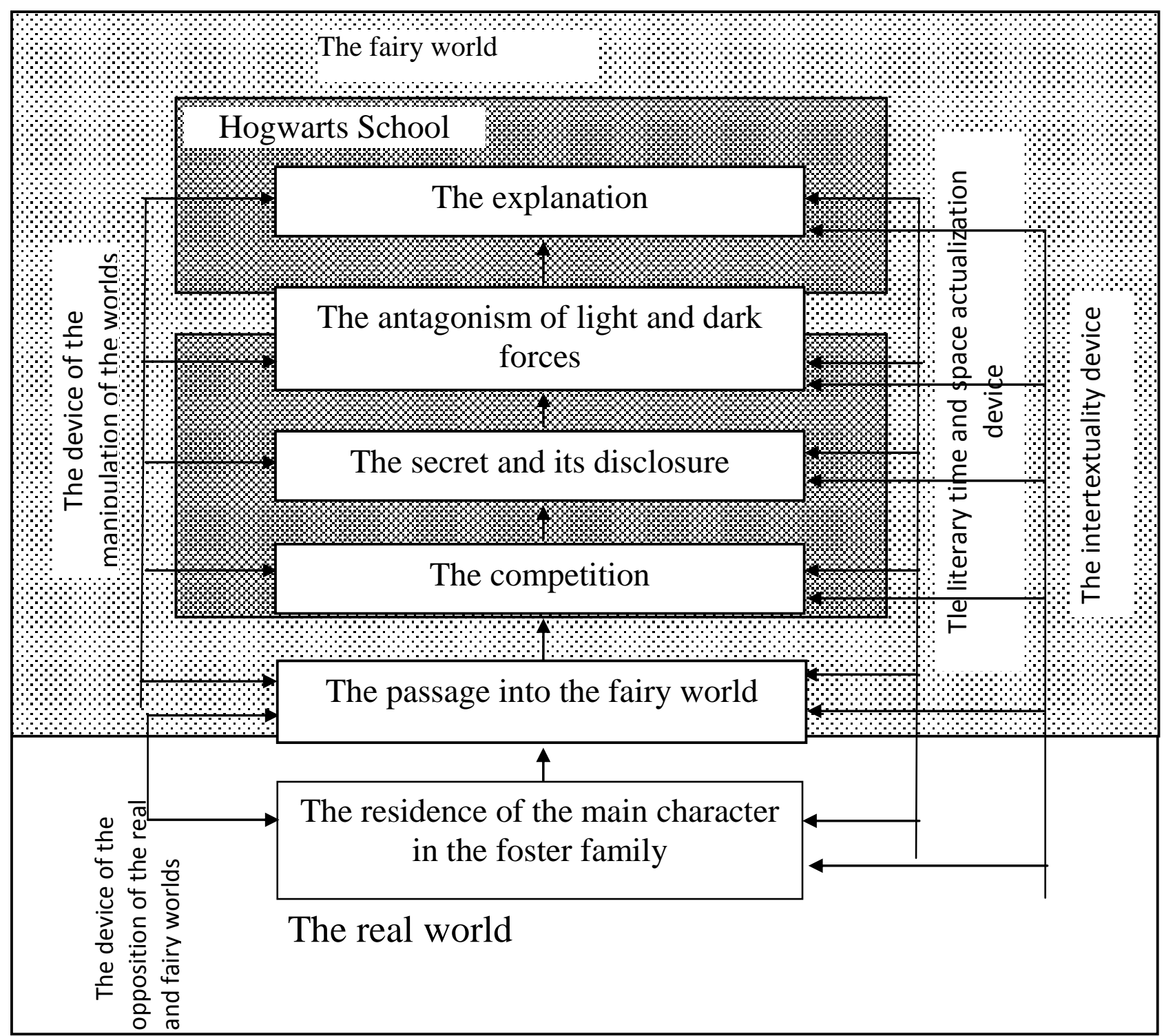

$\square$ - the real world; the fairy world; - Hogwarts School

Figure 1. Compositional plot structure of the text of J.K. Rowling's tales

The arrangement of plot blocks corresponds to the development of general narration of tales showing the line evolution of plot. Under such evolution the unification of compositional blocks is made via compositional devices.

The cognitive analysis of semantics of the literary text and text of tale, in particular, which is understood as unity of content-factual information, containing facts, messages about events, taking place in the real or fictional worlds, and content-conceptual information, transferring to the reader the author's individual understanding of the relations between phenomena (Galperin, 1981), allows to educe the group of key metaphors and metonymies and the uniting them core metaphor, which conveys the sense of text of tales. After P. Stockwell, we consider that megametaphor performs the function of such core metaphor since it passes throughout the text and contributes to understanding its general sense (Stockwell, 2002). As in the folktales in the tales of J.K. Rowling such key metaphor is LIFE IS THE CHOICE OF A PATH.

Analyzing each textual situation we extract textual concepts, the interaction of which is presented in our work in the form of conceptual metaphors and metonymies. The procedure of search of concepts is carried out via semantic analysis of key words of textual situations, i.e. the representatives of concepts. In the basis of educing of schemes of conceptyalizing of different key textual concepts we put the theory of conceptual metaphor by G. Lakoff and M. Johnson, dealing with the ability of a man to think metaphorically and to establish analogies between heterogeneous entities and to overconceptualize them in the terms of other conceptual entities (Lakoff, 1993; Gibbs, 1993; Freeman, 2000). The cognitive approach to the study of metaphor and metonymy has defined their position not only as tropes and figures of speech but also figures of thinking, methods of the sense delivery. On this basis we educe the sense of text of the tale by extracting the conceptual key metaphors and metonymies reconstructed on the basis of the semantic and conceptual analysis of textual fragments in which the information about the central plot events represented in the text is verbalized. 
All five books about Harry Potter represent one story, dedicated to one main theme - CHOICE between good and evil. This theme is connected with the deducted function of tales and lies in the basis of confrontation of the main character and his antagonist Voldemort, the moral slogan of whom is formulated in the phrase:

"There is no good and evil, there is only power..." (Harry Potter and the Philosopher's Stone).

The conceptual megametaphor LIFE IS THE CHOICE OF A PATH is actualized in different plot blocks via textual situations, the sense of which we present in our research in the form of conceptual metaphorical and metonymical schemes, the configurations of which depict the compositional plot structure of the text of the tales (fig. 2).

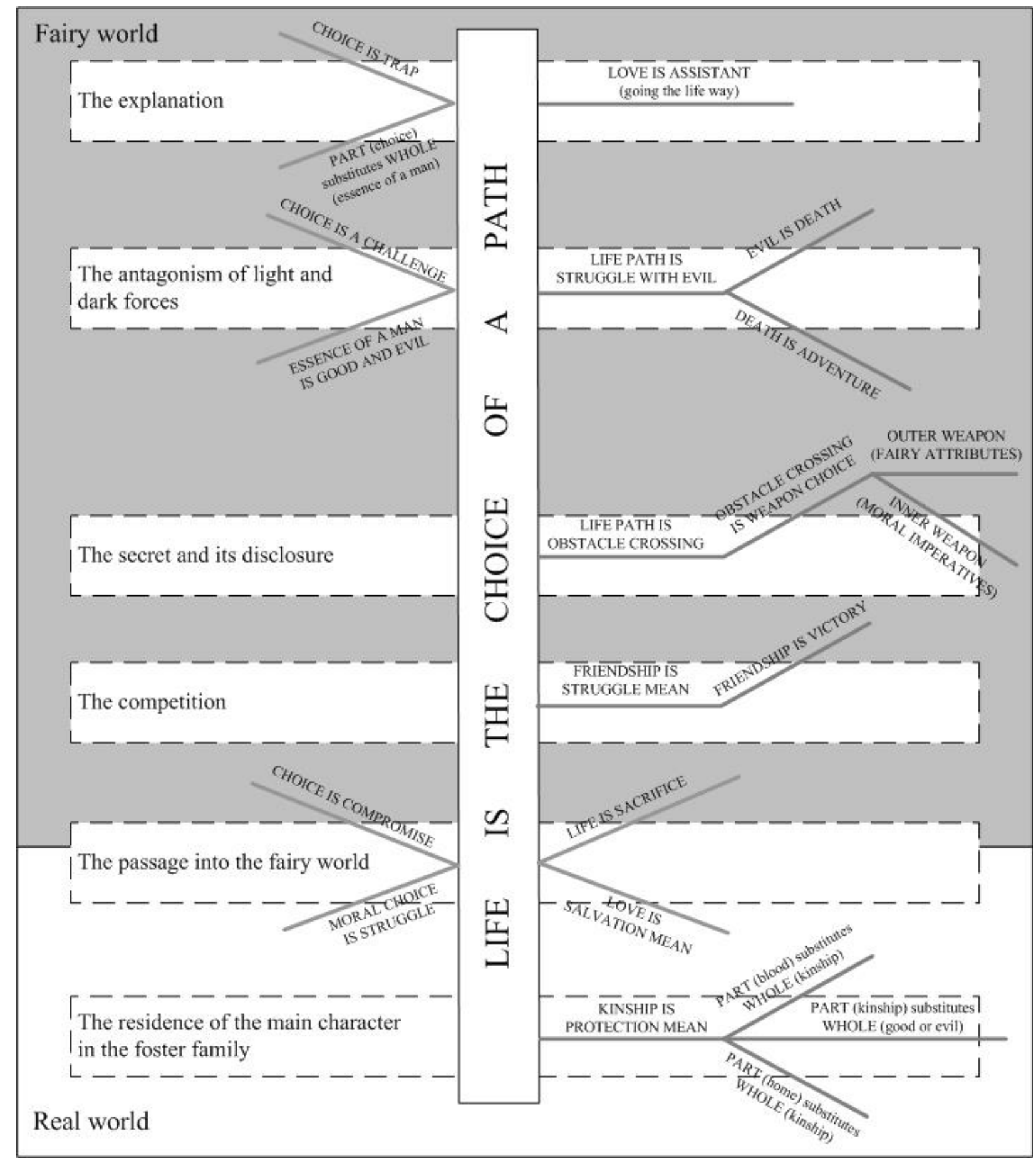

Figure 2. The Model of The Compositional Plot Structure of the Text of

\section{J.K. Rowling's Tales}

The interpretation of text analysis and linguostylistic analysis of textual fragments, composing the plot blocks of the text of J.K. Rowling's tales, allowed us to elicit linguostylistic and compositional speech forms, providing the verbal embodiment of composition as linguistic and cognitive construal. We have established the correlation between the types of tale's plot blocks and verbal means of their actualization. In its turn, the analysis of different kinds of verbal means 
allowed to illustrate genre hybridity of tales and confirm elicited in many linguistic researches the tendencies of development of contemporary English language (Levitsky, 1998; Andrusyak, 2003).

In our work we have defined those phonetic and graphical, lexical and stylistic means, which realize the compositional task of fairy narration and proves the predominance of this or that genre attributes of the text.

Thus, the suspension points serve to actualize the detective constituent of the tales, embodied mainly in the plot block "The secret and its disclosure". As a matter of fact, Harry Potter and his friends are involved into the detective game. They are overwhelmed by all secret and mysterious. They are seized with emotions connected with the disclosure of the secret:

"Snape wants the stone for Voldemort ... and Voldemort's waiting in the Forest ... and all this time we thought Snape just wanted to get rich ... and Voldemort ..." (Harry Potter and the Philosopher's Stone).

Besides, the connection of the suspension points and polysyndeton creates the emotional strain prone to the detective narration.

For the literary narration of the text of J.K. Rowling's tales the following types of the compositional speech forms are the most typical ones: description, reasoning, dialogue and inner monologue. These compositional speech forms perform in the text of tales such functional tasks as the development of subject depictive aspect of narration, including the introduction of the elements of surroundings, delineation of characters, the conveyance of the ironic attitude of the author towards characters. Moreover, the compositional speech forms carry out the emotional state of the character, the psychological experiences connected with the discord of his inner world, thus realizing the psychological constituent of the text of tales.

The complex linguistic and cognitive analysis method proposed in our research opens the prospects for the research of composition of the text of tales of different cultures as well as the artistic texts of other genres. The widening of the practical material of the research by attracting the texts of the English tales of different authors is perspective for educing the tendencies of the development of the contemporary English artistic speech.

\section{References}

Andrusyak, I. (2003). The English Neologisms of the End of XX Century As a Constituent of the Verbal Picture of the World. Kyiv: Prof Press.

Babenko, L.G. (2004). The Linguistic Analysis of the Artistic Text. Moscow: Flinta, Nauka.

Chernets, L. (1999). The Composition. In: Chernets L. (Ed.), The Introduction to the Literary Studies (pp. 115-133). Moscow: High School Press.

Eremeeva, N.F. (1997). Conceptual Space of the English Folk Tales. Cherkassy: ChNU.

Freeman, M. (2000). Poetry and the Scope of Metaphor: Toward a Cognitive Theory of Literature. In: Barcelona, A (Ed.), Metaphor and Metonymy at the Crossroads. A Cognitive Perspective (pp. 253-283). Berlin, New York: Mouton de Gruyter Press.

Galperin, I. (1981). Text As the Object of Linguistic Research. Moscow: Science Press.

Gibbs, R., Jr. (1993). Process and Products in Making Sense of Tropes. In: Ortony, A. (Ed.), Metaphor and Thought (pp. 252-276). Cambridge: Cambridge University Press.

Khalizev, V. (1999). The Plot. In: Chernets L. (Ed.), The Introduction to the Literary Studies (pp. 381-393). Moscow: High School Press.

Lakoff, G. (1993). The Contemporary Theory of Metaphor. In: Ortony, A. (Ed.), Metaphor and Thought (pp. 202-251). Cambridge: University Press.

Levitsky, A. (1998). The Functional Approaches to the Classification of the Units of the Contemporary English. Kyiv: ASA Press.

Lotman, Y.M. (1996). About Poets and Poetry. St. Petersburg: Art-SPB.

Nikonova, V. (2007). The Tragic Picture of the World in the Poetics of Shakespeare. Dnepropetrovsk: DUEP Press.

Propp, V.Y. (1969). The Morphology of the Folk Tale. Moscow: Eastern Literature.

Rastorguyeva, G.V. (2005). In the Search of the Truth In the Message "About Another Person's Intellectual Effort": The Poetical Text. Tambov: TSU.

Stockwell, P. (2002). Cognitive Poetics: An Introduction. London, New York: Routledge Press.

Tomashevsky, B.V. (1959). The Verse and Language: The Philological Sketches. Moscow: Gosizdat. 